\title{
CHANGES IN FITNESS PROFILES DURING A SEASON OF TRACK AND FIELD TRAINING AND COMPETITION
}

\author{
V. THOMAS, D.L.C., Ph.D. and T. REILLY, D.P.E., Ph.D. \\ Physical Education Department, Liverpool Polytechnic
}

\section{INTRODUCTION}

It is generally assumed that track and field athletes improve in physical condition during the competitive season. Much research into fitness training has been concerned with non-athletes undergoing a short period of training (e.g. Durnin, Brockway and Whitcher, 1960; Cureton and Phillips, 1964; Ekblom and co-workers, 1968, and Wilmore and colleagues, 1970) or with athletes of low initial fitness levels (Robinson and Harmon, 1941; Tabakin, Hanson and Levy, 1965; Saltin and co-workers, 1968). Studies on training effects have largely concentrated on cardiovascular and respiratory response to exercise (e.g. Sharkey and Holleman, 1967; Faria, 1970; Davies and Knibbs, 1971; Fox and colleagues, 1973), though changes in psychological parameters have been studied by some investigators (Morgan and colleagues, 1970; Massie and Shephard, 1971). Little emphasis has been placed on the multivariate nature of fitness or the consideration of track and field athletes as a homogenous population. Adams (1968) studied the effects of a season of varsity track and field on selected anthropometric, circulatory and pulmonary parameters.

The measures used were inadequate to embrace the polymorphous conceptualisation of fitness as delineated by Edholm (1969), and Thomas (1970). This limitation would also apply to the study of 18 track athletes by Parnat and co-workers (1975).

\section{SUBJECT AND PROCEDURES}

In the first instance 80 track and field athletes were tested in the laboratory using a 20 -item test battery. Subjects were all members of an athletic club which participates in the National League and which currently held national road-relay titles. Administration took place in May at the beginning of track-season training (T1). Subjects were re-tested five months later at the end of a season of competitive athletics (T2). In the period intervening between tests 13 athletes discontinued training at some time due to injury, occupational factors or emigration and were excluded from the investigation. This reduced the effective experimental population to 67 , aged between 12.2 and $44.6(\bar{x}=19.1)$ years, 54 of whom were male. Between tests subjects performed the training programmes advised and supervised by the club's coaches.
Test items included:

1. Anthropometric data (8 items) obtained according to standardised procedures (Weiner and Lourie, 1969):-

(a) Height and weight were determined using a stadiometer mounted on an Avery Type 3306 $A B V$ weighing machine.

(b) Vital Capacity (VC) and Forced Expiratory Volume in the first second of expiration $\left(F E V_{1}\right)$ were determined using single breath dry spirometry.

(c) Skinfold thicknesses were measured at biceps, triceps, sub-scapular and supra-iliac sites.

2. Performance tests (4 items) conducted according to Clarke (1967):-

(a) Grip strength of right and left hands (Grip R; Grip L).

(b) Vertical jump (Vert $\mathrm{J}$ ) and standing broad jump (SBJ) performances.

3. Circulatory variables (4 items):-

(a) Resting heart rate ( $\mathrm{fH} \mathrm{min}$ ) obtained by palpation over one minute at the end of a 10 minute period lying supine.

(b) Exercise heart rate (Åstrand $\mathrm{fH}$ ) - working heart rate at the end of $5 \mathrm{~min}$. treadmill running at $1^{\circ}$ slope and $10 \mathrm{~km} / \mathrm{hr}$ according to the work protocol of Åstrand (1953). The method of obtaining heart rate is described elsewhere (Reilly, 1975).

(c) Maximum heart rate ( $\mathrm{fH}$ max) determined according to the method of Thomas (1971).

(d) Cardiac Assessment Factor (CAF) computed according to Thomas (1973).

4. Psychological measures:-

(a) Vision (i) distance perception (distance) and (ii) Stereopsis, obtained by means of the Keystone ophthalmic telebinocular.

(b) Visual reaction time (RT) according to Teichner and Krebs (1972) obtained using a Heuer chronoscope. 
(c) Rating of perceived exertion (Borg RPE) during the fifth minute of the treadmill running test according to Borg (1962).

\section{Statistical analysis}

The four skinfold thicknesses were combined to form a composite ( $\Sigma$ skin folds). Means and standard deviations were obtained for each variable at both tests. Changes in each item were investigated using Students ' $t$ ' test. Correlation coefficients for each test-item between T1 and T2 scores were obtained using the Pearson Product Moment method of correlation.

Functional Discriminatory Analysis was performed to investigate whether discrimination was possible between T1 and T2 domains. A significant training effect would be manifested in significant group discriminability. The individual skinfold measurements and the composite variable CAF were excluded from this multi-variate analysis to avoid ill-conditioning the observation matrix. Two tests of discriminability were available using the 1902 Mark II statistical package. These are Rao's ' $F$ ' Test and Bartlett's Chi-squared Test. Separate univariate ' $F$ ' tests were performed initially on the data prior to their inclusion as a whole in the multi-variate assessment. This incidentally provided comparison with the results of Students ' $t$ ' tests. A full description of the statistical procedures in the programme employed was given in Jones (1964).

\section{RESULTS}

Means and standard deviations for all variables T1 and T2 are presented in Table I. Data for all athletes irrespective of sex are pooled. Pulmonary function values were higher than values predicted from height, age and sex using the nomogram of Garbe and McDonnell

\section{TABLE I}

Mean and standard deviation for subjects $(n=67)$ before (T1) and after (T2) a season of track and field training and competition on 20 fitness variables

\section{Test Variable}

Age (years)
Height $(\mathrm{cm})$
Weight $(\mathrm{kg})$
Vital Capacity (l)
FEV $(\ell)$
Biceps fat $(\mathrm{mm})$
Triceps fat $(\mathrm{mm})$
Sub-scapular fat $(\mathrm{mm})$
Supra-iliac fat $(\mathrm{mm})$
Grip R (kg)
Grip L (kg)
Vert J (cm)
SBJ (cm)
fH min (beats/min)
Astrand fH (beat/min)
fH max (beats/min)
CAF
Distance
Stereopsis
RT (ms)
Borg RPE

Before (T1)
Mean \pm S.D.

$19.1 \pm 6.6$

$167.7 \pm 9.7$

$59.5 \pm 11.8$

$4.78 \pm 1.09$

$4.20 \pm 0.89$

$5.1 \pm 1.6$

$5.8 \pm 1.7$

$8.3 \pm 3.0$

$6.2 \pm 2.1$

$40.9 \pm 8.6$

$39.6 \pm 9.5$

$46.1 \pm 7.0$

$198 \pm 21$

$67.7 \pm 11.2$

$167.8 \pm 19.8$

$202.8 \pm 13.0$

$30.7 \pm 4.8$

$\begin{array}{cl}9.2 & \pm 1.9 \\ 10.1 & \pm 3.2 \\ 175 & \pm 21 \\ 10.8 & \pm 2.1\end{array}$

After (T2)

Mean \pm S.D.

$\begin{array}{rll}19.5 & \pm 6.6 & \\ 168.7 \pm 9.1 & .990 \\ 61.0 \pm 11.5 & .983 \\ 4.88 \pm 1.15 & .963 \\ 4.27 \pm 0.96 & .899 \\ & & \\ 4.4 \pm 1.3 & .693 \\ 5.7 \pm 1.8 & .700 \\ 8.4 \pm 3.4 & .874 \\ 6.45 \pm 2.6 & .823 \\ & & \\ 39.8 & \pm 8.8 & .900 \\ 38.2 & \pm 8.4 & .930 \\ 45.2 & \pm 8.0 & .819 \\ 199 & \pm 22 & .884 \\ & & \\ 66.2 & \pm 12.3 & .693 \\ 163.8 & \pm 18.3 & .865 \\ 196.6 & \pm 11.8 & .770 \\ 30.6 & \pm 4.7 & \\ & & .916 \\ 9.4 & \pm 1.65 & .884 \\ 10.5 & \pm 3.1 & .576 \\ 172 & \pm 20 & .350 \\ 10.9 & \pm 2.1 & \end{array}$

"Significance level $=p<.05$. All other parameters showed no significant difference. tThese co-efficients were all at the level of $A=0.325$ for $p<0.005$.

tTest-Retest Correlation Co-efficient

990

963

899

700

874

930

819

693

865 
(1964). Resting heart rates were close to the values generally quoted for normal individuals. Maximum heart rates at T1 were higher than the figures of Saltin and Asstrand (1967) for Swedish international male and female athletes, or the figures given by Shephard (1971) for young men and women. Reaction times were similar to those reported by Reilly $(1975$, op. cit.) for top-class soccer players.

Univariate analysis using the ' $t$ '. test revealed nonsignificant results in all tests except for $\mathrm{fH}$ max. This significant effect was a mean reduction of 6.2 beats $/ \mathrm{min}$. in the maximum heart rate. Decreases of 1.7 beats $/ \mathrm{min}$. in resting heart rate and of 4 beats $/ \mathrm{min}$. in the treadmill running tests were non-significant. The slight but nonsignificant increases in height $(1 \mathrm{~cm})$, weight $(1.5 \mathrm{~kg})$, and Vital Capacity (0.11) were probably due to growth in the younger subjects in the population studied.

Results of test/retest correlations are included. These were highly significant for all variables $(p<.005)$. The lower correlation coefficients were observed in two psychological variables - Borg RPE $(R=.350)$ and $R T$ $(R=.576)$. Results for all other variables were in general similar to values for quoted reliability coefficients for each test. These high correlation coefficients suggest relative stability of fitness during the 5 months of the competitive session.

The univariate ' $F$ ' tests showed non-significant results for all variables except $\mathrm{fH}$ max. This is in agreement with the results of the ' $t$ ' tests. Discrimination between T1 and T2 matrices was non-significant $(p>.05)$. This indicates that when the test scores are pooled for consideration as a whole no training effect was observed.

\section{DISCUSSION}

The significant decrease in $\mathrm{fH}$ max may tentatively be ascribed to a change in the environmental temperature between tests. Ambient temperature in the laboratory was not controlled but was subjectively felt by $E$ to be higher at $\mathrm{T} 1$ than $\mathrm{T} 2$. An increase in $\mathrm{fH}$ with increased environmental heat is well documented (Brouha, 1960). As the heat stress effects are not additive at the higher levels of work intensity (Le Blanc, 1967) and no changes were found in the Astrand $\mathrm{fH}$, this explanation is untenable.

Alternatively, the decrease may represent a typical training effect as observed by Ekblom (1969) who found a reduction of 7 beats $/ \mathrm{min}$. with a training programme. Wilmore et al $(1970$, op. cit.) found a similar reduction of 7.1 beats $/ \mathrm{min}$. resulting from a 10 week programme of jogging. This decrease did not occur in another investigation by Ekblom et al (1968, op. cit.) with 16 weeks of physical training. A third explanation would be an unwillingness on the Subject's part at T2 to exercise to exhaustion. In the light of the high test-retest correlation coefficients this reluctance would in general be consistent across individuals.

Apart from the decline in $\mathrm{fH}$ max no changes were found. This result was not expected and requires summary explanation.

Prior to testing at T1 all subjects had participated in a vigorous conditioning programme. They were tested im. rnediately prior to the commencement of systematic track and field training. The competitive season started immediately, reaching a climax during July and August with the major championships and continuing until October with Trophy and League competitions. Training during the competitive season was biased towards specificity training i.e. training routines specific to the athletes' competitive event, with lesser emphasis on general conditioning work. These specific effects might be obscured when track and field athletes are studied as a homogenous population or when parameters designed to monitor grosser aspects of fitness are employed.

Though a training effect would be expected in track and field athletes during the competitive season, this expectation was not observed by other investigators in other sports. Coleman, Kreuzer and Juvenal (1974) observed stability of circulatory efficiency over a prolonged period of competitive sport in college basketball players. Hanson (1975) found that improvements in general fitness acquired during pre-competitive training were partially lost during a 3 months' competitive season in 9 international skiers. The decline was attributed in part to lack of adequate training time during the period of long-distance travel and racing. These conditions did not apply in our present study. Investigations on professional soccer players using a 72 item test battery found that in general fitness profiles improved significantly during a six-week period of pre-season training and that this training effect was maintained but not improved during the competitive season (Reilly, 1975, op. cit.). The stability of fitness was attributed to absence of overload during critical component routines of the training programme.

Alternatively, improvement in fitness measures during the competitive season has been reported in Czechoslovak speed-canoers (Cermak, Kuta and Parizkova, 1975), and in American wrestlers (Shaver, 1974). Bachman and Horvath (1969) reported pulmonary function changes in swimmers over a four month period but no change over the same period in wrestlers. Thompson (1959) observed a decrease in body fat and an increase in muscle mass in varsity college football players during a season. Adams (1968, op. cit.) found no changes in a range of anthropometric measures and no significant reduction in resting or post-bench-step terminal heart rate over a season of varsity track and field. A significant reduction in post-bench-step recovery counts was noted. 
It seems that training effects during the competitive season differ between sports, and probably between levels of participation. Also the intra-competitive season improvement may not obtain where pre-season conditioning has been rigorous. This is substantiated by the findings of Parnat, Viru and Nurmekivi (1975, op. cit.) who noted in a study of 19 track athletes that aerobic work capacity varied more extensively during the competitive season in the case of runners with low initial fitness.

A third possibility is the existence of imperfections in the training regime employed by the club coaches. This might be due to organisational difficulties at training sessions where the attendance of active athletes, particularly in the youth and minor sections outstrips the capacity of available coaches to cater for the large numbers involved. The result is that insufficient attention is given to individual needs. This has been reflected in the plea for more qualified coaches to assist at training sessions.

Another explanation may be in a periodisation of fitness within the competitive season. The major championships are held in mid-season and track and field athletes aim to achieve peak conditioning at this time. A gradual process of reversibility of training effects may obtain for the remainder of the season. In experimental paradigms that compare fitness profiles at the beginning and at the end of the competitive season, the peak of conditioning effects may be missed. Further research is required to clarify this aspect.

\section{CONCLUSION}

1. Fitness profiles did not improve significantly in 67 track and field athletes during a 5 months' period of training and competition.

2. A decrease in maximum heart rate was noted during the competitive season.

3. The stability of fitness profiles in the athletes may be due to high initial levels of conditioning, inefficient training regimes, or test spacing which missed possible peaks in fitness.

\section{REFERENCES}

ADAMS, W. C., 1968. Effect of a season of varsity track and field on selected anthropometric, circulatory and pulmonary function parameters. Res. Quart., 33, 5-15.

ÅSTRAND, P. O., 1953. A study of capacity for hard muscular work of 17 to 19 year old male youths. ? Arbeitsphysiologie, 15, 251-254.

BACHMAN, J. C. and HORVATH, S. M., 1969. Pulmonary function changes which accompany athletic conditioning programs. Res. Quart., 39, 235-239.

BORG, G., 1962. Physical performance and perceived exertion. Gleerups: Lund.

BROUHA, L., 1960. Physiology in Industry. Pergamon: London.

CERMAK, J., KUTA, I., and PARIZKOVA, J., 1975. Some predispositions for top performance in speed canoeing. J.Sports Med.\& Phys. Fit. 15, 243-251.

CLARKE, H. H., 1967. Application of Measurement to Health and Physical Education. Prentice-Hall: New Jersey.

COLEMAN. A. E., KREUZER, P., FRIEDRICH, D. W. and JUVENAL, J. P., 1974. Aerobic and anaerobic responses of male college freshmen during a season of basketball. J.Sports Med.and Phys. Fitness, 14, 26-31. .

CURETON, T., and PHILLIPS, E., 1964. Physical fitness changes in middle-aged men attributable to equal 8-week periods of training, non-training and retraining. J.Sports Med.and Phys. Fitness, 4, 1-17.

DAVIES, C. T. M. and KNIBBS, A. V., 1971. The training stimulus: the effects of intensity, duration and frequency of effort on maximum aerobic power output. Int.Z.angew.Physiol., 29, 299-305.

DURNIN, J. V. G. A., BROCKWAY, J. M. and WHITCHER, H. W., 1960. Effects of a short period of training of varying severity on some measurements of physical fitness. J.Appl.Physiol., 15, 161-165.

EDHOLM, O. G., 1969. Fitness for what? Proc.Roy.Soc.Med., 62, 617-620. 
EKBLOM, B., ASTRAND, P. O., SALTIN, B., STENBERG, J. and WALLSTROM, B., 1968. Effect of training on circulatory response to exercise. J.Appl.Physiol., 24, 518-528.

EKBLOM, B., 1969. Effect of physical training on the oxygen transport system in man. Acta Physiol.Scand., Suppl., 328.

FARIA, I. E., 1970. Cardiovascular response to exercise as influenced by training of various intensities. Res. Quart., 41, 44-50.

FOX, E. L., BARTELS, R. L., BILLINGS, C. E. MATHEWS, D. K., BASON, R., and WEBB, W. M., 1973. Intensity and distance of interval training programmes and changes in aerobic power. Med.Sci.Sports, 5, 18-22.

GARBE, D. R. and MCDONNELL, H., 1964. Lung function testing: an introduction to routine clinical tests illustrated with the use of the vitalograph. Vitalograph Ltd., Buckingham.

HANSEN, J. S., 1975. Decline of physiologic training effects during the competitive season in members of the US Nordic ski team. Med.Sci.Sports, 7, 213-216.

JONES, K. J., 1964. The Multivariate Statistical Analyser. Harvard University Press, Harvard.

Le BLANC, J. A., 1957. Use of heart rate as an index of work output. J.Appl.Physiol., 10, 275-280.

MASSIE, J. F. and SHEPHARD, R. J., 1971. Physiological and psychological effects of training - a comparison of individual and gymnasium programs, with a characterization of the exercise "drop-out". Med.Sci.Sports, 3, 110-117.

MORGAN, W. P., ROBERTS, J. A., BRAND, F. R. and FEINERMAN, A. D., 1970. Physiological effect of chronic physical activity. Med.Sci.Sports, 2, 213-217.

PARNAT, J., VIRU, A., and NURMEKIVI, A., 1975. Repeated assessment of aerobic and anaerobic work capacity in runners. J.Sports Med.and Phys. Fitness, 15, 13-19.

REILLY, T. P., 1975. An ergonomic evaluation of occupational stress in professional football. Unpublished Ph.D. thesis. Liverpool Polytechnic.

ROBINSON, S. and HARMON, P. M., 1941. The effects of training and of gelatin upon certain factors which limit muscular work. Amer.J.Physiol., 133, 1961-1969.

SALTIN, B. and ÅSTRAND, P. O., 1967. Maximum oxygen uptake in athletes. J.Appl.Physiol., 23, 353-358.

SALTIN, B., BLOMOVIST, G., MITCHELL, J. H., JOHNSON, R. L., WILDENTHAL, K., and CHAPMAN, C. B., 1968. Response to exercise after bed rest and after training. Circulation, 38, Suppl. 7., 1.78.

SHARKEY, B. J. and HOLLEMAN, J. P., 1967. Cardio-respiratory adaptations to training at specified intensities. Res.Quart., 38, 698-704.

SHAVER, L. G., 1974. Effects of a season of varsity wrestling on selected physiological parameters. J.Sports Med. and Phys. Fitness, 14, 266-271.

SHEPHARD, R. J., 1971. Endurance Fitness. University of Toronto Press, Toronto.

TABAKIN, B. S., HANSON, J. S. and LEVY, A. M., 1965. Effect of physical training on the cardiovascular and respiratory response to graded upright exercise in distance runners. Brit. Heart J., 27, 205-210.

TEICHNER, W. H., and KREBS, M. J., 1972. Laws of the simple visual reaction time. Psychol. Rev., 79, 344-358.

THOMAS, V., 1970. The fitness evaluation of international standard sportsmen. Respiratory News Bull., 16, 21-26.

THOMAS, V., 1971. The tolerance of extreme physical stress in sportsmen. Unpublished Ph.D., thesis. University of Surrey. 
THOMAS, V., 1973. A test of cardiac function during strenuous exercise. Brit.J.Sports Med., 7, 139-141.

THOMPSON, C. W., 1959. Changes in body fat, estimated from skinfold measurements of varsity college football players during a season. Res. Quart., 30, 87-93.

WEINER, J. S., and LOUIRE, J. A. 1969. Human Biology: A Guide to Field Methods. Blackwell, Oxford.

WILMORE, J. H., ROYCE, J., GIRONDOLA, R. N., KATCH, F. I. and KATCH, V. L., 1970. Physiological alterations resulting from a 10-week program of jogging. Med.Sci.Sports, 2, 7-14. 